Conceptual Knowledge in Introductory Calculus Author(s): Paul White and Michael Mitchelmore Source: Journal for Research in Mathematics Education, Vol. 27, No. 1 (Jan., 1996), pp. 79-95 Published by: National Council of Teachers of Mathematics

Stable URL: http://www.jstor.org/stable/749199

Accessed: 19/01/2009 02:38

Your use of the JSTOR archive indicates your acceptance of JSTOR's Terms and Conditions of Use, available at http://www.jstor.org/page/info/about/policies/terms.jsp. JSTOR's Terms and Conditions of Use provides, in part, that unless you have obtained prior permission, you may not download an entire issue of a journal or multiple copies of articles, and you may use content in the JSTOR archive only for your personal, non-commercial use.

Please contact the publisher regarding any further use of this work. Publisher contact information may be obtained at http://www.jstor.org/action/showPublisher?publisherCode=nctm.

Each copy of any part of a JSTOR transmission must contain the same copyright notice that appears on the screen or printed page of such transmission.

JSTOR is a not-for-profit organization founded in 1995 to build trusted digital archives for scholarship. We work with the scholarly community to preserve their work and the materials they rely upon, and to build a common research platform that promotes the discovery and use of these resources. For more information about JSTOR, please contact support@jstor.org. 


\title{
CONCEPTUAL KNOWLEDGE IN INTRODUCTORY CALCULUS
}

\author{
PAUL WHITE, Australian Catholic University \\ MICHAEL MITCHELMORE, Macquarie University
}

\begin{abstract}
Responses to word problems involving rates of change were collected on four occasions during and after 24 hours of concept-based calculus instruction given to a group of first-year university students, all of whom had studied calculus in secondary school. The number of students who could symbolize rates of change in noncomplex situations increased dramatically. However, there was almost no increase in the number who could symbolize rates of change in complex items or in items that required modeling a situation using algebraic variables. Detailed analysis revealed three main categories of error, in all of which variables are treated as symbols to be manipulated rather than as quantities to be related. We surmise that the students had developed an "abstract-apart" concept of a variable rather than the "abstract-general" concept that is needed for the successful study of calculus.
\end{abstract}

Changes in technology, the qualifications of teachers, and the mathematical competence of students have led many to question the role of traditional calculus courses in the curriculum. There is, in particular, much concern about the large numbers of students taking calculus and the rote, manipulative learning that takes place (Cipra, 1988; Steen, 1988; White, 1990). The value of skill-based calculus courses has also come under fire because computers and calculators now perform most (if not all) of the manipulative procedures taught in such courses (Steen, 1988; Tall, 1987a). Several studies (Heid, 1988, 1989; Hickernell \& Proskurowski, 1985; Judson, 1990; Palmiter, 1991) have shown how using the computer as a tool for performing the procedures of calculus and algebra can free students to explore applications. Other studies (Hsaio, 1984/85; Tall, 1986) have used graphics to explore secants and tangents to curves in order to build up a sound concept of a derivative. The general tendency is for less emphasis on skills and greater emphasis on underlying concepts.

Research into the understanding of calculus has shown a whole spectrum of concepts that cause problems for students. In particular, student difficulties with the abstract concepts of rate of change (Orton, 1984), limit (Cornu, 1981; Tall \& Vinner, 1981), tangent (Vinner, 1982; Tall, 1987b), and function (Dreyfus \& Eisenberg, 1982; Even, 1993; Vinner, 1983; Vinner \& Dreyfus, 1989) are well documented. These concepts involve mathematical objects or processes specific to calculus. Another aspect that needs to be considered is the question of what other concepts are involved in applying calculus knowledge.

This paper is based on the doctoral research of the first author (White, 1992), which was carried out under the supervision of the second author. Funding to support postdoctoral publications from the Australian Government through the Australian Catholic University is gratefully acknowledged. 
The purpose of the present study was to investigate the performance on some calculus application problems of a group of students who had previously experienced a traditional introductory calculus course and, thereby, to infer the role of their conceptual knowledge (or lack of it) in solving application problems.

\section{ABSTRACTION AND CONCEPTUAL KNOWLEDGE}

A feature of all advanced mathematics is the need for abstract concepts, that is, concepts formed by the process of abstracting. "Abstracting" is used here in the sense of Skemp (1986), who describes it as the process of identifying certain invariant properties in a set of varying inputs. The act of abstracting is based on generalizing these properties to other inputs, but it is seen as qualitatively different from simply identifying patterns in a set of examples. It is a many-to-one function where generalizations are synthesized from many inputs to form a new abstraction. Dreyfus (1991) summarizes the process as a sequence of generalizing $\rightarrow$ synthesizing $\rightarrow$ abstracting.

Sfard $(1991,1992)$ and Dubinsky (1991) have further highlighted the qualitative difference between generalizations and abstractions, pointing out that abstracting is in effect a move to a higher cognitive plane. Sfard $(1991,1992)$ describes a threephase model similar to the sequence of Dreyfus: interiorization $\rightarrow$ condensation $\rightarrow$ reification. The interiorization phase occurs when some process is performed on familiar mathematical objects. The condensation phase occurs when the process is condensed into more manageable units. Both of these phases are said to be operational because they are process-oriented. Reification is the leap from an operational mode to a structural mode where a process becomes an object in its own right. Dubinsky (1991) also describes this leap from dynamic process to static object as a form of reflective abstraction; he calls the leap "encapsulation."

Kieran (1992) has applied Sfard's model to the learning of algebra. Initially, students operate with numbers; patterns in arithmetic are then interiorized or generalized and eventually give way to algebraic expressions that become objects in their own right. Tall (1991b) notes that $2+3 x$ can be considered as the process of adding 2 to the product of 3 and $x$ and also as the object that is the result of the process. He also gives the example (cited in Kieran, 1992) that an operational (process) orientation results in $2(a+b)$ being seen as quite different from the resultant object $2 a+2 b$. Tall (1991b) argues that until algebraic expressions can be conceived as mathematical objects as well as processes on objects, algebraic manipulation can be a source of conflict. Gray and Tall (1994) cite examples in a wide range of mathematics where the same symbols are used to represent both a mathematical process and the resultant mathematical object. The amalgam of process, resultant object, and common symbol used to represent both is defined as an elementary "procept." They hypothesize that successful mathematical thinkers can think proceptually; that is, they can comfortably deal with symbols as either process or object.

Once an abstraction has occurred, the generalizing $\rightarrow$ synthesizing $\rightarrow$ abstracting sequence can be repeated. The sequence certainly occurs in concept formation at all levels in mathematics, but it is a feature of advanced concepts that they are 
based on several repetitions. Each repetition has led to a higher order of abstraction and a further removal from what Skemp (1986) calls "primary concepts," that is, those that are formed by direct experience.

Conceptual knowledge in mathematics has been characterized by Hiebert and Lefevre (1986) as relationships between mathematical objects and hence appears to be similar to what Skemp (1976) calls "relational understanding." Hiebert and Lefevre also make a key distinction between relationships that are constructed at the same level of abstraction as the constituent concepts and therefore do not involve an increase in abstraction, and those "reflective relationships" that are constructed at a higher level. They use the term "abstract" to refer to the degree to which a relationship is freed from specific contexts. Because advanced mathematical concepts are the result of several abstraction sequences, the network of relationships among concepts can be extremely complex.

Hiebert and Lefevre describe procedural knowledge as knowledge of standard learned procedures that can be applied when some type of recognizable cue is presented. A key word for such procedures is "after" in the sense of "after this step comes the next step" (Hiebert \& Lefevre, 1986, p. 8). Procedural knowledge may or may not be supported by conceptual knowledge. Unsupported procedural knowledge is similar to Skemp's (1976) "instrumental understanding," which he describes as knowing rules without knowing why they work.

Steen (1988) and Cipra (1988) argue that skills-based calculus courses result in rote, manipulative learning. The result is instrumental understanding or unsupported procedural knowledge. As Skemp points out, skills-based courses are very efficient if the only criterion is the ability to perform routine manipulations. It is the application problems that appear to call on conceptual knowledge, and it is clearly the hope of those who design concept-based calculus instruction that students' ability to solve such problems will be improved as a result.

\section{APPLICATIONS, MODELING, AND VARIABLES}

In calculus, the context of an application problem may be a realistic or artificial "real-world" situation, or it may be an abstract, mathematical context at a lower level of abstraction than the calculus concept that is to be applied. We shall restrict ourselves here to problems that can be solved using algebra and symbolic calculus. In solving such problems, the given situation is first translated from the context to the abstract level of the calculus, the abstract problem is then solved, and the solution is finally translated back to the context (Tall, 1991a). It is the first step that most obviously calls on conceptual knowledge because it depends on the identification not only of the appropriate concepts in the given context but also of the relationships among them. (The abstract problem might well be solvable using procedural knowledge alone, and the back-translation would probably require only the same understandings developed in the first step.) The identification of appropriate concepts might involve the selection of one or more symbolized variables from among several presented, or it might require the solver to define one or more new variables. 
The identification of relationships requires the establishment of some algebraic relations among the variables or the selection of some calculus concept involving the variables (such as a derivative) and its expression in symbolic form. Only then can known manipulations be carried out.

For the purpose of this article, we shall refer to the definition of new variables and the symbolic expression of relations between variables as (algebraic) modeling. The selection of a calculus concept and its expression in symbolic form we shall call symbolization. Modeling and symbolization together constitute translation.

Translation as defined above encompasses both algebraic and calculus concepts. In particular, the use of symbols to represent changing quantities is crucial. The fact that students find this difficult in calculus contexts is supported by the work of Frid (1992). She showed that although students are able to manipulate symbols and perform operations with symbols when doing calculus problems, they do not generally use symbols to represent concepts. No other research on students' use of symbols in calculus has been found, so we have to rely on algebra research to guide our expectations.

Küchemann (1981) suggests that very few students understand variables at his highest conceptual level. Eisenberg (1991) agrees and in support quotes the research of Wagner (1981), who showed that $15 \%$ of 16 -year-old students treated two equations as totally different when the only difference was the letter used to represent the variable. Such a superficial understanding of variables is in line with Kieran's (1989) view that one of the main difficulties in learning algebra centers on accommodating the meaning of the letters involved. Booth (1989) suggests that the required meaning is often neglected in the teaching and learning of algebra, so that many students only learn manipulation rules without reference to the meaning of the expressions being manipulated. It is a matter of some interest to find out whether students who aspire to the advanced mathematical thinking involved in calculus have an adequate concept of a variable.

\section{METHOD}

\section{Sample}

The sample consisted of 40 first-year, full-time university mathematics students. A prerequisite for entry to the university mathematics program was a satisfactory result in the final high school examination for a mathematics course that contained a large component of calculus. None of these students had finished in the top $10 \%$ in that examination; most were between the 50th and 80 th percentiles.

Calculus was taught to the students by the first author for 4 hours per week over a 6-week period as half of a one-semester course. It followed the approach of Barnes (1992), in which rates of change are investigated using graphs of physical situations. The secant was seen as an average rate of change, the tangent as an instantaneous rate of change, and the derivative was defined as the instantaneous rate of change. 


\section{Test Items}

Because a preliminary study had suggested that the crucial step in successfully solving calculus application problems was identifying an appropriate derivative, four items were constructed that dealt with rates of change and maximization. Items 1 and 2 required the student to find a specific rate of change, and Items 3 and 4 involved using a derivative to maximize or minimize a given quantity.

Each of the four items was structured in four versions (A, B, C, D) so that the manipulation required to solve each version was essentially the same. The difference between the versions was that each involved successively less translation. Hence, version A required translating all rates to an appropriate symbolic derivative, whereas version $\mathrm{D}$ had all information presented in symbolic form. The four versions allowed the various translation steps required in each item to be isolated. Algebraic modeling was not required in Item 1 and was rather obvious in Item $2 \mathrm{~A}$ but was substantial in Items 3 and 4 in both versions A and B.

The four versions of each item are shown in Table 1.

\section{Procedure}

Students were tested on four occasions: before, during, immediately after, and then 6 weeks after the calculus course. The 40 students were divided into four approximately parallel groups of 10 , on the basis of their performance in an algebra course completed the previous semester. The students were unaware of the groupings. Four tests were constructed, each of which included four questions: one version of each of the four items. Each version of each item occurred on one and only one test, and each test had only one question in each version. These four tests were administered in a cyclic fashion to each of the four groups over the four data collections, so that students attempted different items each time, but data were still available for the same pool of items at every test occasion.

In addition, four students per group were selected before the start of the research and were interviewed within 3 days of each of the four written data collections. These interviews served to clarify and expand on written responses so that student reasoning could be better identified. The interviews also established that students were unaware that they were answering different versions of the same four items at each data collection.

\section{RESULTS}

Table 2 shows the number of correct responses to all items at each data collection. Performance on version A at the first data collection shows that the students could not initially apply their knowledge of calculus, even though they had met similar items the year before in high school. The general pattern of difficulties for the four versions of each item confirms that they were correctly ordered in terms of the amount of translation required to solve them. 

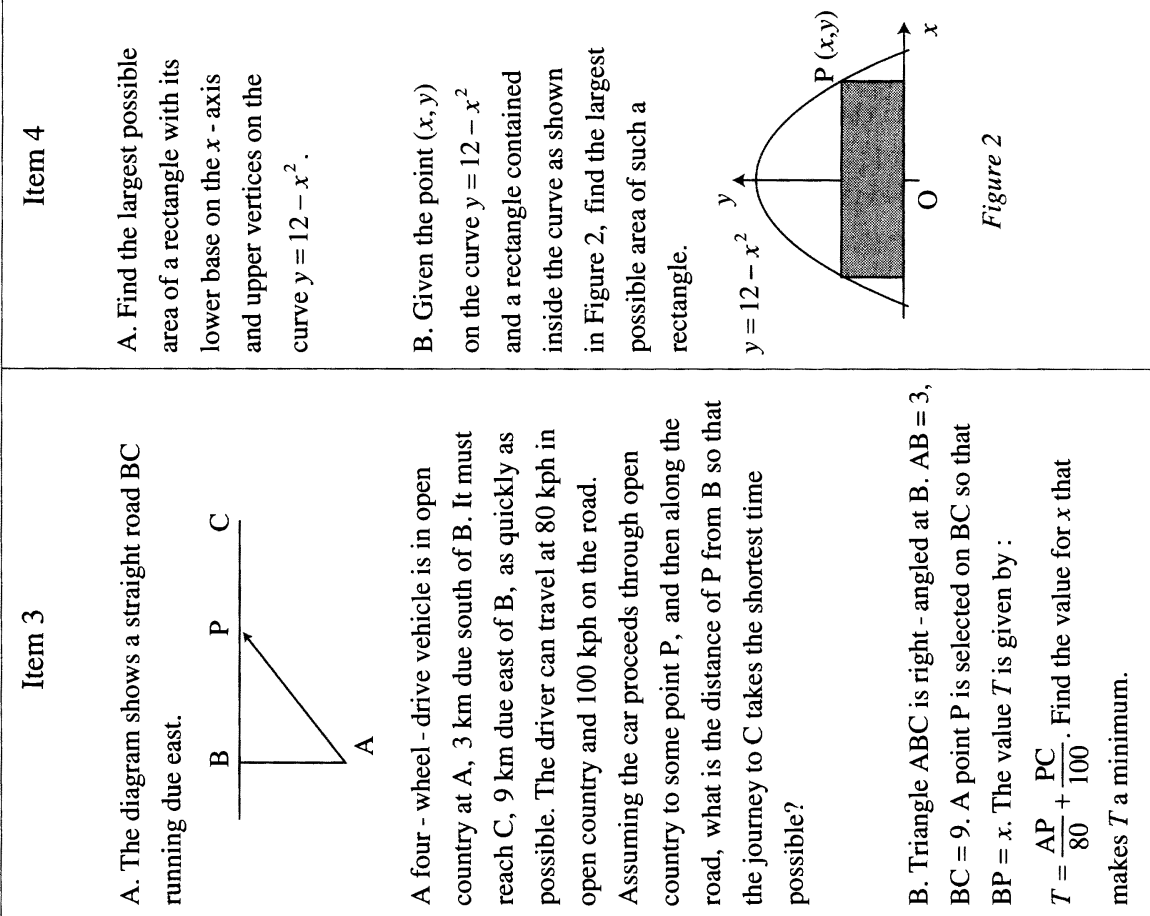

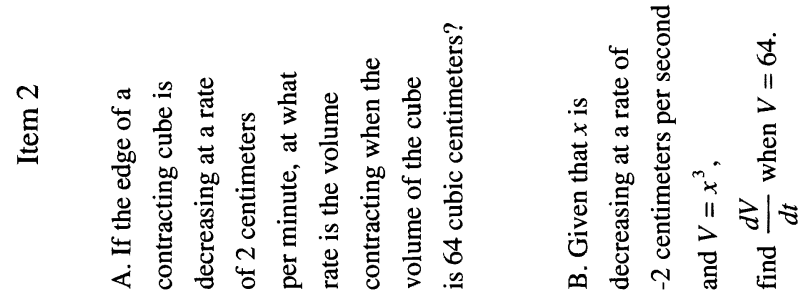

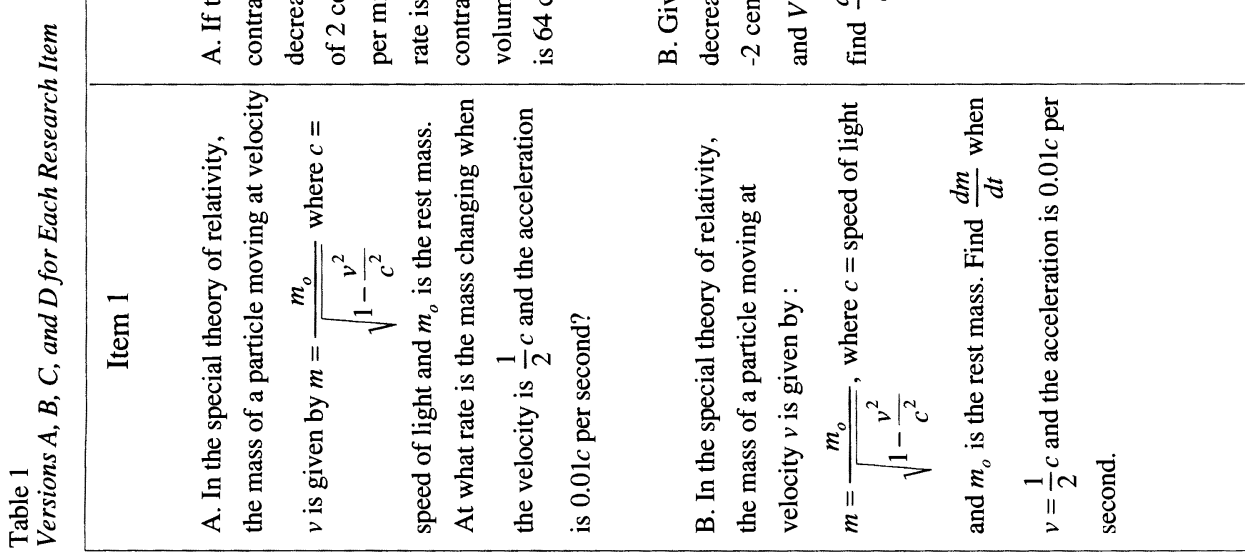




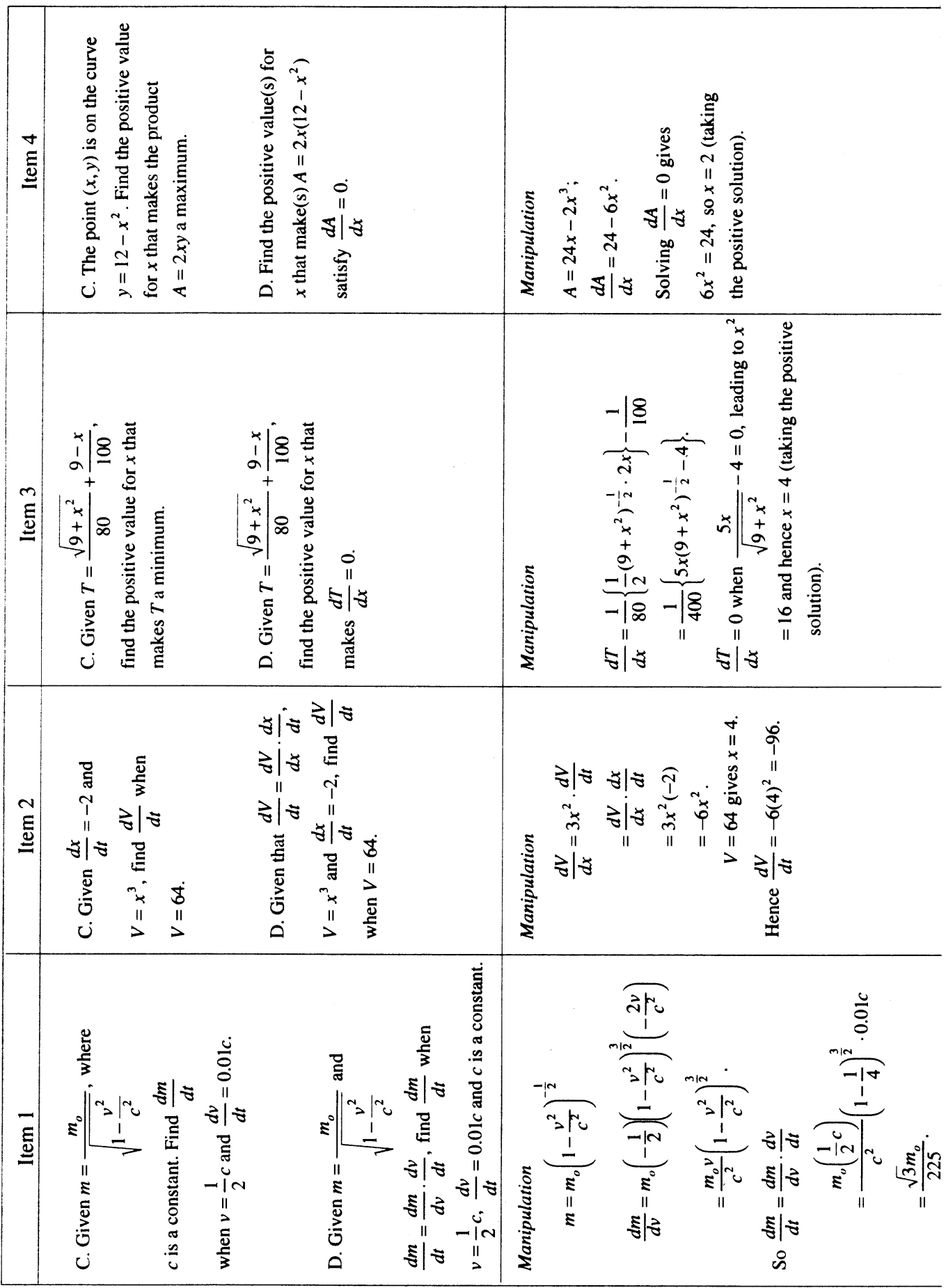


Table 2

Number of Correct Responses by Item, Data Collection Period, and Version

\begin{tabular}{|c|c|c|c|c|c|c|c|c|c|c|c|c|c|c|c|c|}
\hline \multirow[b]{2}{*}{ Item } & \multicolumn{4}{|c|}{ Collection 1} & \multicolumn{4}{|c|}{ Collection 2} & \multicolumn{4}{|c|}{ Collection 3} & \multicolumn{4}{|c|}{ Collection 4} \\
\hline & A & B & $\mathrm{C}$ & $\mathrm{D}$ & A & $\mathrm{B}$ & $\mathrm{C}$ & $\mathrm{D}$ & A & $\mathrm{B}$ & $\mathrm{C}$ & D & A & B & $\mathrm{C}$ & $\mathrm{D}$ \\
\hline 1 & 0 & 0 & 1 & 1 & 0 & 1 & 1 & 1 & 1 & 2 & 2 & 3 & 0 & 3 & 3 & 1 \\
\hline 2 & 1 & 1 & 2 & 4 & 0 & 2 & 7 & 4 & 4 & 9 & 6 & 7 & 5 & 4 & 6 & 7 \\
\hline 3 & 0 & 1 & 1 & 2 & 1 & 1 & 2 & 2 & 1 & 3 & 4 & 6 & 2 & 2 & 2 & 6 \\
\hline$\underline{4}$ & 0 & 0 & 3 & 7 & 1 & 1 & 0 & 9 & 2 & 1 & 5 & 8 & 1 & 1 & 3 & 10 \\
\hline
\end{tabular}

Note. Maximum 10 in each cell.

The improvement in the number of correct responses in data collections 3 and 4 (after instruction) was substantial, although average performance still only exceeded $50 \%$ for Item 2 . The large number who improved suggests that the teaching was a positive factor, but the equally large number who did not points to strong inhibiting factors. The following discussion addresses both factors inhibiting success and areas where improvement occurred. Results for Items 1 and 2 (rates of change) and Items 3 and 4 (maximization) are initially presented and discussed separately.

\section{Rates of Change}

Items 1 and 2 required only trivial modeling, and symbolization was required only in versions $\mathrm{A}$ and $\mathrm{B}$. Table 3 presents data pooled over these two versions.

Table 3

Number of Correct Symbolizations and Correct Solutions (in Parentheses) to Versions A and B of Items 1 and 2 by Data Collection Period

\begin{tabular}{lcccc}
\hline & \multicolumn{4}{c}{ Data Collection Period } \\
Item & 1 & 2 & 3 & 4 \\
\hline 1 & $0(0)$ & $1(1)$ & $3(3)$ & $4(3)$ \\
2 & $4(2)$ & $2(2)$ & $18(13)$ & $18(9)$ \\
\hline
\end{tabular}

Note. Maximum 20 for both entries in each cell.

Two clear patterns emerge from Table 3 . In the more complex Item 1 , few were able to correctly symbolize at any time; but those who did were almost always correct. In the less complex Item 2, something quite different occurred. In the last two collections, almost all could correctly symbolize, but only slightly more than $60 \%$ of these students could then proceed to a correct solution.

Error analysis pointed to a different dominant error in the two items. The dominant error was prevalent in all versions of each item.

In Item 1 the dominant error was to substitute

$$
v=\frac{1}{2} c
$$

before differentiating. Sample responses of this type follow:

Student 1: Substitutes 


$$
v=\frac{1}{2} c
$$

and tries to differentiate. Written response is

$$
m=\frac{m_{o}}{\sqrt{\frac{3}{4}}} ; \frac{d m}{d t}=\frac{d m_{o}}{d t}=0 .
$$

Student 2: Substitutes

$$
v=\frac{1}{2} c
$$

and does not differentiate. Written response is

$$
m=\frac{m_{o}}{\sqrt{1-\frac{c^{2}}{4 c^{2}}}}=\frac{m_{o}}{\sqrt{\frac{3}{4}}} ;
$$

the rate of change is $1 / 4$.

In Item 2 the dominant error centered on students' inability to correctly use $V=$ 64. Sample responses include the following:

Student 3: Leaves the answer at $-6 x^{2}$, indicating that the 64 has not been used. Student 4: Gives two answers, one for $V=x^{3}$ and one for $V=64$. Written response is

when $V=x^{3}$ and

$$
\frac{d V}{d t}=-6 x^{2}
$$

$$
\frac{d V}{d t}=0
$$

when $V=64$.

On the surface, the errors of Students 3 and 4 appear to be different. Interview comments indicated, however, that both errors had the same source: the inability to reconcile the variable expression $V=x^{3}$ with the particular value $V=64$. The following are sample comments from students who gave responses like that of Student 3:

Student 5: The $V=x^{3}$ and the $V=64$ at the same time confused me. I didn't know which one to use.

Student 6: Is the 64 the starting volume?

Table 4 gives the number of responses showing the dominant error in each item. The decrease in the number of dominant errors in Item 1 and the increase in Item 2 seemed to result from instruction as students became more aware of the need for a derivative. In Item 1, more students symbolized an incorrect derivative in the last two collections instead of substituting first. In Item 2, more students symbolized the correct derivative in the last two collections, thus providing themselves with more opportunities for making the dominant error. 
Table 4

Number of Responses Showing the Dominant Error in Items 1 and 2 (all Versions) by Data Collection Period

\begin{tabular}{lcccc}
\hline \multicolumn{5}{c}{ Data Collection Period } \\
Item & 1 & 2 & 3 & 4 \\
\hline 1 & 21 & 17 & 8 & 8 \\
2 & 7 & 7 & 11 & 15 \\
\hline
\end{tabular}

Note. Maximum 40 in each cell.

Discussion of Items 1-2. The main inhibiting factor to success in Items 1 and 2 seems to have been an underdeveloped concept of a variable. In both items, students were apparently unable to distinguish between a general relation and a statement of a specific value. Other errors suggested that this confusion was part of a wider tendency, which we shall call the manipulation focus, in which students base decisions about which procedure to apply on the given symbols and ignore the meanings behind the symbols. Interview comments showed that manipulation focus errors were not just bad luck, but that students were actively looking for symbols to which they could apply known manipulations. The following student comments illustrate this focus on Item 1:

Student 7: I couldn't see how to get the $t$ 's out of the $v$ 's.

Student 8: You have to differentiate, but there is a $v$ and a $c$, and they're both given. I don't know which one to use.

Student 9: There is a change, so I thought of

$$
\frac{d m}{d v}
$$

because $v$ was the only variable there.

There were some manipulation focus errors in Item 2 as well:

Student 10: What does rate mean? It means derivative ... with time. It must be

$$
\frac{d r}{d t}
$$

[Why $r$ ?] $r$ for rate.

Student 11: $V=64$, how can I differentiate the $V$ ?

The manipulation focus and the relative complexity of Items 1 and 2 suggest an explanation for the pattern previously noted in Table 3. Being able to symbolize derivatives involves forming relationships between concepts and should therefore be indicative of conceptual knowledge. However, the data for Item 2 suggest that in a noncomplex situation, the formulation of relationships can be based on visible symbols alone and so does not require a sound conceptual base. The low number of variables makes symbolizing straightforward, because there is virtually only one choice of dependent and independent variable. However, in the more complex Item 1, the necessary relationships require a more solid conceptual base; the variables must be linked 
to derivatives and to each other in a context where manipulation cues alone do not suffice. As a result, to correctly symbolize the appropriate derivative a student must have an overview of how all the variables fit together and not just zoom in on some visible symbols.

\section{Maximization}

A key feature of Items 3 and 4 is the need for algebraic modeling in versions A and $\mathrm{B}$. Table 5 gives the pooled data for these two versions.

Table 5

Number of Correct Modelings and Correct Solutions (in Parentheses) to Versions A and B of Items 3 and 4 by Data Collection Period

\begin{tabular}{lcccc}
\hline & \multicolumn{3}{c}{ Data Collection Period } \\
Item & 1 & 2 & 3 & 4 \\
\hline 3 & $2(1)$ & $3(2)$ & $4(4)$ & $5(4)$ \\
4 & $0(0)$ & $2(1)$ & $4(3)$ & $2(2)$ \\
\hline
\end{tabular}

Note. Maximum 20 for both entries in each cell.

As can be seen from Table 5, there were few changes in the number of responses showing correct modeling across the four data collections. In fact, most students either could not identify and symbolize an appropriate variable by translating one or more quantities in the item to an appropriate symbolic form and so define a useable function or, if they could, were unable to make use of their definitions. Such a result was not surprising in the more complex Item 3, as the following interview comments show.

Student 12:It's the type where you get an equation, find the derivative, and make it equal to zero, but I couldn't get the equation. [There had been no written response.]

Student 13: I want a minimum so I want to put

$$
\frac{d T}{d x},
$$

but I didn't have an $x$, so I didn't bother. [Written response contained a number of attempts at modeling the situation.]

Student 14: I need to find an expression for AP and PC in terms of $x$. How, I couldn't tell you. [Written response contained a modeling attempt.]

The lower success rate for the less complex Item 4 appears at first to be rather odd. Error analysis showed that the main reason was what we call the $x, y$ syndrome. Students seized on the equation $y=12-x^{2}$ and found

$$
\frac{d y}{d x}
$$

even though it was totally inappropriate: 
Student 15: I tried to find $x$ and $y$. [Why

$$
\left.\frac{d y}{d x} ?\right]
$$

There's nothing else. It can only be

$$
\frac{d y}{d x} \text {. }
$$

Student 16: The procedure for finding a maximum is to find

$$
\frac{d y}{d x}
$$

and set it to zero.

Student 17: [Drew the rectangle with correct coordinates on all four vertices, but made no attempt to model the area in terms of these.] I know I have to differentiate and set it to zero, but it doesn't make sense here.

Examination of version C of Items 3 and 4, where the information is presented in symbolic form but the appropriate symbolic derivative still needs to be selected, shows some interesting results (see Table 6). After instruction, most students were able to select the correct derivative in Item 3 (although they frequently made manipulation errors). In fact, the complexity of Item 3 lies at the modeling stage; after that, there is effectively only one choice of dependent and independent variables. However, instruction had a much weaker effect on Item 4. As can be seen by comparing Tables 5 and 6 , providing the modeled information in symbolic form did not make Item 4 easier; the key factor was selecting the correct derivative in the face of the $x, y$ syndrome.

Table 6

Number of Students With the Correct Derivative and the Correct Solution (in Brackets) to Version C of Items 3 and 4 by Data Collection.

\begin{tabular}{lcccc} 
& \multicolumn{4}{c}{ Data Collection Period } \\
Item & 1 & 2 & 3 & 4 \\
\hline 3 & $3(1)$ & $3(2)$ & $10(4)$ & $8(2)$ \\
4 & $3(3)$ & $0(0)$ & $5(5)$ & $3(3)$ \\
\hline
\end{tabular}

Note. Maximum 10 for both entries in each cell.

Another result of interest is hidden in Table 5. Of the 17 responses that were correct for versions $A$ and $B$ of Items 3 and 4, 8 occurred in version A and 9 in version $\mathrm{B}$. In version $\mathrm{A}$, these 8 responses were the only ones to correctly identify appropriate variables; that is, all the students who selected and symbolized appropriate variables were totally correct. However, in version $\mathrm{B}$, there were 5 other responses that correctly modeled the situation using the already defined variables but made some error at a later stage.

Discussion of Items 3-4. In the $x, y$ syndrome, the procedure for maximizing a function has apparently been remembered in terms of the symbols used when it was first learned, rather than as a process based on the rate of change of the function. 
This shows that the $x, y$ syndrome is another example of the manipulation focus identified for Items 1 and 2 . As in other examples, students treat the visible symbols as candidates for well-known manipulation rules instead of considering the meaning of the symbols.

Because so few students were able to define appropriate variables in Items $3 \mathrm{~A}$ and $4 \mathrm{~A}$ and because those who did were always completely correct, there is a strong suggestion that defining and using new variables is qualitatively different from relating explicitly given variables in symbolic form, which is all that is required in version B of Items 3 and 4 . It can be argued that defining and using new variables involves forming relationships at a higher level of abstraction than relating those already given. Defining variables in a modeling situation indicates that the solver is making choices with some plan in mind-a plan that has not been laid out in visible cues. Defining new variables therefore involves relationships at a higher level of generality than the concepts they connect, that is, what Hiebert and Lefevre (1986) call "reflective relationships."

For example, in Item 3A, information about speed and distance must be pulled together to form a relationship that leads to minimum time. Alone, the link between speed, distance, and time is no more general than the cued information. The introduction of Pythagoras's theorem is also no more general than the cue of the rightangled triangle leading to it. However, choosing an appropriate distance to define as the independent variable so that the speed-distance-time relationship and Pythagoras's theorem can both be employed suggests that those relationships themselves have been related. The process requires that the solver reflect on a number of relationships, and seeing how to combine them indicates the existence of a relationship at a higher level of abstraction.

\section{GENERAL DISCUSSION}

Responses to the four research items strongly suggest that a major source of students' difficulties in applying calculus lies in an underdeveloped concept of a variable. In particular, students frequently treat variables as symbols to be manipulated rather than as quantities to be related. Three examples of such a "manipulation focus" have been identified: failure to distinguish a general relationship from a specific value (the difficulty with $V=64$ in Item 2); searching for symbols to which to apply known procedures regardless of what the symbols refer to (substituting first in Item 1); and remembering procedures solely in terms of the symbols used when they were first learned (the $x, y$ syndrome in Item 4).

Students showing the manipulation focus have a concept of variable that is limited to algebraic symbols; they have learned to operate with symbols without any regard to their possible contextual meaning. We call such concepts "abstractapart" (Mitchelmore, 1994; Mitchelmore \& White, 1995; White, 1992; White \& Mitchelmore, 1992). Discussing a similar phenomenon, Tall (1991a) calls the accumulation of new rules, learned by rote and added to existing knowledge without any attempt to integrate the rules with old ideas, "disjunctive generalization." Such a description fits our definition of abstract-apart. Whatever term we use, the 
important characteristic is that abstract-apart ideas are formed without any true abstraction (and, for that matter, without any generalization).

We call concepts that are formed by a generalizing $\rightarrow$ synthesizing $\rightarrow$ abstracting sequence (Dreyfus, 1991) "abstract-general." Only abstract-general ideas can be linked in conceptual knowledge (Hiebert \& Lefevre, 1986). In practice, a continuum rather than a dichotomy exists between abstract-apart and abstract-general. Abstractapart concepts are rarely completely devoid of meaning, and the generality of an abstractgeneral concept depends on the variety of contexts from which it has been abstracted. The two extremes are, however, often confused and we believe it is important to distinguish them. For example, most readers would undoubtedly say that the $D$ versions of our research items are abstract. By abstract, do they mean that these items are removed from reality and therefore meaningless, or do they mean that they could refer to a variety of contexts? The two different views of abstraction lead to different views of what constitutes mathematics and, hence, of how mathematics should be taught.

When symbols represent abstract-apart concepts, as in the manipulation focus, they are not related to any mathematical objects at a lower level of abstraction that could give them meaning. Relationships between the symbols can therefore only be superficial, that is, they can only be based on what the symbols look like; and learned rules can only be applied on the basis of the visible symbols available. An abstract-apart concept might be adequate to deal with routine symbolic procedures, but the limitations of such purely procedural knowledge (Hiebert \& Lefevre, 1986) become apparent when the symbols have a specific contextual meaning. In particular, symbolizing a rate of change in complex problem situations requires the existence of abstract-general concepts because the symbols used to represent general variables and derivatives have to be related to the specific variables and rate of change that occur in that situation (necessarily at a lower level of abstraction). Modeling a given situation using algebra may represent an even higher level of abstraction than the several abstract-general concepts that may be invoked.

It is easy to see why many students prefer to learn in an abstract-apart fashion and become more comfortable with decontextualized problems than with contextual problems. Abstract-apart ideas are easier to learn because they are limited to a purely symbolic context (sometimes only the two symbols $x$ and $y$ ). All the decontextualized problems students can solve look very similar, and the appropriate procedures are therefore easy to formulate. Success in such a narrow context can even lead to a sense of satisfaction. By contrast, learning abstract-general concepts requires the formation of links among a wide variety of superficially different contexts. This must take longer and must be intellectually more demanding. But the resulting abstractgeneral concepts can be "seen" in contexts where there are no visible cues, and the learned relationships can then be used to solve the most diverse problems.

The present study illustrates the significance of encapsulation (Dubinsky, 1991) or reification (Sfard, 1991, 1992) and the importance of thinking proceptually (Gray $\&$ Tall, 1994) in the formation of abstract-general concepts. Students who can use defined variables but cannot identify and define their own variables would seem to be using symbols essentially to express the process of relating one variable to another. These students are still at the condensation phase of developing their concept of a 
variable. On the other hand, students who can create variables to solve complex problems would seem to have reified variables. Interview comments for Item 3 such as "I knew I wanted time and had some distances and speeds. So I looked for a connection and got time and distances so gave $x$ for the distance" show that such students are using variables as a tool/object in the higher level process of problem solving. The findings that such students never made manipulation errors is consistent with the view that reification can only occur after extensive successful experience using variables in the operational mode.

\section{IMPLICATIONS}

In the present study, almost the only detectable result of 24 hours of instruction intended to make the concept of rate of change more meaningful was an increase of manipulation-focus errors in symbolizing a derivative. Most students appeared to have an abstract-apart concept of a variable that was blocking meaningful learning of calculus. Our findings parallel those reported in school algebra research (Booth, 1989; Eisenberg, 1991; Kieran, 1989; Küchemann, 1981). Given that calculus students are more mature and more highly selected, this is a most disappointing result.

The inevitable conclusion is that a prerequisite to a successful study of calculus is an abstract-general concept of a variable at or near the point of reification. Even a concept-oriented calculus course is unlikely to be successful without this foundation. However, just as much experience manipulating and modeling arithmetical expressions must precede reification of algebraic expressions (Kieran, 1992), students probably need to spend a considerable amount of time using algebra to manipulate relations before they can achieve a mature concept of a variable (White $\&$ Mitchelmore, 1993). It is not, therefore, realistic to attempt to provide adequate remedial activities within a calculus course for those students who have an abstract-apart concept of a variable. Either entrance requirements for calculus courses should be more stringent in terms of variable understanding, or an appropriate precalculus course should be offered at the university level.

\section{REFERENCES}

Barnes, M. (1992). Investigating change. Melbourne, Australia: Curriculum Corporation.

Booth, L. R. (1989). A question of structure. In S. Wagner \& C. Kieran (Eds.), Research issues in the learning and teaching of algebra (pp. 57-59). Reston, VA: National Council of Teachers of Mathematics.

Cipra, B. A. (1988). Calculus: Crisis looms in mathematic's future. Science, 239, 1491-1492.

Cornu, B. (1981). Apprentissage de la notion de limite: Modèles spontanés et modèles propres. [Learning the limit concept: Individual and suitable models.] Actes du Cinquième Colloque du Groupe Internationale PME (pp. 322-326). Grenoble: Université de Grenoble.

Dreyfus, T. (1991). Advanced mathematical thinking processes. In D. O. Tall (Ed.), Advanced mathematical thinking (pp. 25-41). Dordrecht, The Netherlands: Kluwer.

$\rightarrow$ Dreyfus, T., \& Eisenberg, T. (1982). Intuitive functional concepts: A baseline study on intuitions. Journal for Research in Mathematics Education, 13, 360-380.

Dubinsky, E. (1991). Reflective abstraction in advanced mathematical thinking. In D. O. Tall (Ed.), Advanced mathematical thinking (pp. 95-126). Dordrecht, The Netherlands: Kluwer.

Eisenberg, T. (1991). Functions and associated learning difficulties. In D. O. Tall (Ed.), Advanced mathematical thinking (pp. 140-152). Dordrecht, The Netherlands: Kluwer. 
$\rightarrow$ Even, R. (1993). Subject-matter knowledge and pedagogical content knowledge: Prospective secondary teachers and the function concept. Journal for Research in Mathematics Education, 24, 94-116.

Frid, S. (1992). Calculus students' use of symbols. In T. Cooper (Ed.), New directions in algebra research, Presentation 4. Queensland University of Technology: Centre for Mathematics and Science Education.

$\rightarrow$ Gray, E. M., \& Tall, D. O. (1994). Duality, ambiguity, and flexibility: A "proceptual" view of simple arithmtic. Journal for Research in Mathematics Education, 25, 116-140.

Heid, M. K. (1988). Resequencing skills and concepts in applied calculus using the computer as a tool. Journal for Research in Mathematics Education, 19, 3-25.

Heid, M. K. (1989). How symbolic mathematical systems could and should affect precollege mathematics. Mathematics Teacher, 82, 410-419.

Hickernall, F., \& Proskurowski, W. (1985). The use of microcomputers in the teaching of calculus. Collegiate Microcomputer, $I I I(2), 111-124$.

Hiebert, J., \& Lefevre, P. (1986). Conceptual and procedural knowledge in mathematics: An introductory analysis. In J. Hiebert (Ed.), Conceptual and procedural knowledge: The case of mathematics (pp. 1-23). Hillsdale, NJ: Erlbaum.

Hsaio, F. S. (1984/85). A new CAI approach to teaching calculus. Computers in Mathematics and Science Teaching, 4 (2), 29-36.

Judson, P. (1990). Using computer algebra systems in mathematics courses. Journal of Mathematical Behavior, 9, 153-158.

Kieran, C. (1989). The early learning of algebra: A structural perspective. In S. Wagner \& C. Kieran (Eds.), Research issues in the learning and teaching of algebra (pp. 33-56). Reston, VA: National Council of Teachers of Mathematics.

Kieran, C. (1992). The learning and teaching of school algebra. In D. Grouws (Ed.), Handbook of research on mathematics teaching and learning (pp. 390-419). New York: Macmillan.

Küchemann, D. E. (1981). Algebra. In K. M. Hart (Ed.), Children's understanding of mathematics: 11-16 (pp. 102-119). London: John Murray.

Mitchelmore, M. C. (1994). Abstraction, generalisation and conceptual change in mathematics. Hiroshima Journal of Mathematics Education, 2, 45-46.

Mitchelmore, M. C., \& White, P. (1995). Abstraction in mathematics: Conflict, resolution and application. Mathematics Education Research Journal, 7(1), 50-68.

Orton, A. (1984). Understanding rate of change. Mathematics in School, 13(5), 23-26.

Palmiter J. R. (1991). Effects of computer algebra systems on concept and skill acquisition in calculus. Journal for Research in Mathematics Education, 22, 151-161.

Sfard, A. (1991). On the dual nature of mathematical conceptions: Reflections on processes and objects as different sides of the same coin. Educational Studies in Mathematics, 22, 1-36.

Sfard, A. (1992). Operational origins of mathematical objects and the quandary of reification: The case of function. In G. Harel \& E. Dubinsky (Eds.), The concept of function (pp. 59-84). Washington, DC: Mathematical Association of America.

Skemp, R. R. (1976). Relational understanding and instrumental understanding. Mathematics Teaching, 77, 20-26.

Skemp, R. R. (1986). The psychology of learning mathematics (2nd ed.). Harmondsworth, UK: Penguin.

Steen, L. (Ed.) (1988). Calculus for a new century. Washington, DC: Mathematical Association of America.

Tall, D. O. (1986). Building and testing a cognitive approach to calculus using interactive computer graphics. Unpublished doctoral dissertation, University of Warwick, Warwick, UK.

Tall, D. O. (1987a). Whither calculus? Mathematics Teaching, 11, 50-54.

Tall, D. O. (1987b). Constructing the concept image of a tangent. In J. Bergeron, N. Herscovics, \& C. Kieran (Eds.), Proceedings of the 11th International Conference for the Psychology of Mathematics Education, (Vol. 3, pp. 69-75). Montréal, Canada: Université de Montréal.

Tall, D. O. (1991a). The psychology of advanced mathematical thinking. In D. O. Tall (Ed.), Advanced mathematical thinking (pp. 1-24). Dordrecht, The Netherlands: Kluwer.

Tall, D. O. (1991b). Reflections. In D. O. Tall (Ed.), Advanced mathematical thinking (pp. 251-259). Dordrecht, The Netherlands: Kluwer. 
Tall, D. O., \& Vinner S. (1981). Concept image and concept definition in mathematics, with particular reference to limits and continuity. Educational Studies in Mathematics, 12, 151-169.

Vinner, S. (1982). Conflicts between definitions and intuitions: The case of the tangent. In A. Vermandel (Ed.), Proceedings of the Sixth International Conference for the Psychology of Mathematics Education (pp. 24-28). Antwerp, Belgium: Universitaire Instelling Antwerpen.

Vinner, S. (1983). Concept definition, concept image and the notion of function. International Journal of Mathematical Education in Science and Technology, 14, 239-305.

$\rightarrow$ Vinner, S., \& Dreyfus, T. (1989). Images and definitions for the concept of a function. Journal for Research in Mathematics Education, 20, 356-366.

$\rightarrow$ Wagner, S. (1981). Conservation of equation and function under transformations of variables. Journal for Research in Mathematics Education, 12, 107-118.

White, P. (1990). Is calculus in trouble? Australian Senior Mathematics Journal, 4, 105-110.

White, P. (1992). Conceptual knowledge in rates of change and derivative. Unpublished doctoral dissertation, Macquarie University, Sydney, Australia.

White, P., \& Mitchelmore, M. C. (1992). Abstract thinking in rates of change and derivative. In B. Southwell, B. Perry, \& K. Owens (Eds.), Proceedings of the 15th Annual Conference of the Mathematics Education Research Group of Australasia (pp. 574-581). Richmond, New South Wales: Mathematics Education Research Group of Australasia.

White, P., \& Mitchelmore, M. C. (1993). Aiming for variable understanding. Australian Mathematics Teacher, 49(4), 31-33.

\section{AUTHORS}

PAUL WHITE, Senior Lecturer in Mathematics and Mathematics Education, Australian Catholic University, Castle Hill NSW 2154, Australia; e-mail: whi600@acuone.acu.edu.au

MICHAEL C. MTCHELMORE, Senior Lecturer in Mathematics Education, Macquarie University NSW 2109, Australia 